\title{
A reflexão sobre a prática e o discurso de professores: um estudo de caso
}

\author{
Reflecting on teachers' practice and discourse: a case study
}

\author{
Ayrton Araújo Kiill
}

Rogério Marques Ribeiro

Resumo: Este artigo apresenta uma discussão acerca do discurso de professores que ensinam Matemática sobre a temática "professor reflexivo". A investigação foi realizada com professores de diferentes níveis de ensino e que atuam no município de Guarulhos. Metodologicamente, esta pesquisa está alicerçada nos princípios do estudo de caso, e para a coleta de dados utilizamos diferentes instrumentos, como o uso de questionário e as entrevistas. As análises de nossos dados nos permitiram observar que os discursos dos professores participantes desta investigação convergem, em parte, com as discussões teóricas que adotamos para nossa análise. Os dados nos permitem inferir, também, que estes professores pouco se envolvem com as leituras e discussões que poderiam auxiliá-los, teoricamente, no processo de formação de um professor reflexivo.

Palavras-chave: Professor reflexivo. Discurso do professor. Reflexão sobre a prática.

Abstract: This article discusses the discourse of educators who teach Mathematics with a focus on reflexive teaching. The investigation involved teachers of different levels that teach in the municipality of Guarulhos. The methodology of this research relies on case study principles, and different tools were used for data collection, like a questionnaire and interviews. The data analysis process allowed us to observe that the discourse of the teachers who participated in this investigation partially corroborates the theoretical discussions that we adopted for our analysis. Based on the data collected, we were able to infer that the teachers have little engagement in readings and discussions that might help them theoretically in their formation process as reflexive teachers.

Keywords: Reflexive teacher. Teacher discourse. Reflective practice.

Ayrton Araújo Kiill Mestrando em Ensino de Ciência e Matemática pelo Instituto Federal de Educação, Ciência e Tecnologia de São Paulo (IFSP). São Paulo, Brasil.

\section{Introdução}

Estudos acerca do professor reflexivo, da reflexão sobre a prática, e demais temáticas envolvendo o conceito de reflexão, como os produzidos por Dewey (1979), Schön (2000), Pimenta e Ghedin (2002) e Alarcão (2011), têm sido apresentados há muitas décadas na área de Educação e de Educação Matemática. Para Pimenta (2002), a partir da década de 1990 se intensificaram os estudos sobre estas temáticas em países como Portugal, Estados Unidos e Brasil.

(iD) orcid.org/0000-0003-4316-629X $\bowtie$ ayr.ton.a.k15@hotmail.com Doutor em Ed Rogério Marques Ribeiro Instituto Federal de Educação, Ciência e Tecnologia de São Paulo (IFSP), campus Guarulhos. São Paulo, Brasil. (iD) orcid.org/0000-0002-8214-7342 $\triangle$ rogeriomarques@me.com Recebido em 05/10/2019 Aceito em 03/12/2019 Publicado em 28/01/2020

Apesar desta temática ter sido muito explorada por diferentes pesquisas, entendemos que a prática de alguns professores ainda pode não estar pautada pelas discussões que foram 
realizadas, mesmo quando alguns destes se autodenominam ser professores reflexivos. Assim, ao se propor uma discussão sobre esta temática, observamos que alguns professores, sejam eles da Educação Básica ou do Ensino Superior, consideram-se reflexivos em sua prática docente, e essa consideração por parte do professor nos leva a fazer questionamentos do tipo: (i) Por que esse professor se considera reflexivo?. (ii) O que, em sua prática, pode ser destacado como uma ação característica de um professor reflexivo? (iii) Esse professor apresenta algum argumento teórico, ao se considerar reflexivo, ou sua afirmação está pautada apenas em sua prática docente?

Questionamentos desta natureza surgem, de forma até natural, quando nos deparamos com um professor que se considera um professor reflexivo, e nos desperta grande interesse em buscar elementos que nos permita responder a estes questionamentos, haja vista a complexidade teórica envolvida nessa discussão, e que vai além de uma consideração que tenha apenas sua prática como elemento basilar para sua argumentação, pois, de certa maneira, todos os professores podem se considerar como reflexivos, mas a questão a qual devemos nos ater é sobre como eles refletem (ZEICHNER, 1993).

Neste sentido, a pesquisa que realizamos buscou evidenciar se os professores sujeitos desta investigação revelam, em seus discursos, uma prática de reflexão crítica e intencional proveniente de suas práticas docentes quando se deparam, em suas atividades profissionais, com as incertezas comumente presentes no ambiente escolar, contribuindo para que a reflexão se constitua como uma prática não apenas de repensar suas ações, mas que de fato possibilite criar atividades diferentes daquelas às quais os professores possam estar habituados a praticar.

Pesquisas na área da Educação Matemática, como a desenvolvida por Neves e Bittar (2015), têm destacado a importância de se compreender a prática reflexiva do professor como uma prática capaz de redimensionar a sua postura em suas ações pedagógicas, contribuindo para a conscientização de suas crenças e para que seja um profissional crítico quanto aos desafios que Ihe são propostos no âmbito educacional.

A partir destas considerações é que propomos discutir o tema "professor reflexivo" com alguns professores que se auto intitulam como professores reflexivos, com a finalidade de buscar elementos que nos permitam, por meio das discussões, compreender as suas razões e crenças que possam responder aos questionamentos que formulamos anteriormente.

Destacamos, assim, que temos como percurso norteador para esse trabalho a investigação sobre o discurso de alguns professores, frente a alguns questionamentos sobre sua 
prática docente e que envolvem as características próprias de professores reflexivos. Sendo assim, apresentamos as discussões realizadas ao longo deste trabalho, dividindo-as em quatro momentos, a saber: uma discussão sobre professor reflexivo; desenho metodológico da investigação; análise dos dados; e considerações.

\section{Uma discussão sobre professor reflexivo}

Ao nos referirmos às discussões que envolvem a reflexão do professor sobre sua prática docente buscamos destacar a importância de se considerar a reflexão crítica e intencional advinda da prática e da ação do professor quando este defronta-se, em sua prática docente, com as incertezas e angústias do ambiente escolar.

Pimenta (2002) destaca, ainda, que a reflexão do professor abrange outros estados, como o de dúvidas, de hesitação e de perplexidade, sendo que a reflexão deve ter como um de seus focos a busca por soluções pertinentes a esses sentimentos.

Esta característica, quando se olha para a reflexão do professor, é observada, inicialmente, nos trabalhos de Dewey (1979) apud Pimenta e Ghedin (2002, p. 2), que caracterizou o pensamento reflexivo como alternativa para a melhoria profissional dos professores, a partir da consideração do "pensamento reflexivo como a melhor maneira de pensar, e o define como sendo a espécie de pensamento que consiste em examinar mentalmente 0 assunto e dar-lhe consideração séria e consecutiva".

Neste sentido, o professor precisa observar, investigar e refletir sobre suas ações e episódios que ocorreram no âmbito da sala de aula, com o objetivo de resolver os problemas que forem percebidos. Assim, a busca por solução das incertezas, das angústias ou de dúvidas pode ser vista como um "fator básico e orientador em todo o mecanismo da reflexão" (PIMENTA e GHEDIN, 2002, p. 24).

Esta necessidade, entretanto, não pode ser apenas considerada dentro de uma preocupação vista como uma racionalidade técnica, haja vista que para professores técnicos a reflexão "caracteriza-se por um processo de alienação da realidade na qual o docente está inserido, destituído de uma consciência política e de uma formação cidadã que contribua para transformar a si e a realidade na qual está inserido" (ARAUJO, 2008, p. 3). 
As discussões propostas por Pimenta e Ghedin (2002) e Araújo (2008) vão ao encontro das ideias de Alarcão (2011), quando esta autora destaca que o professor reflexivo deve ser um profissional que reflita sobre qual sua função na sociedade e por quais motivos ele atua, devendo, ainda, ser um profissional crítico, e não apenas um mero reprodutor de ideias. Alarcão (2011, p. 41) destaca, ainda, que "é central, nessa conceptualização, a noção do profissional como uma pessoa que, nas situações profissionais, tantas vezes incertas e imprevistas, atua de forma inteligente e flexível, situada e reativa".

Esta atuação, destacada por Alarcão (2011), encontra respaldo para o seu desenvolvimento nos momentos de reflexão defendidos por Shön (2000). Para este autor, há três momentos de reflexão do professor sobre a sua própria prática, que são: reflexão na ação, reflexão sobre a ação e reflexão sobre a reflexão na ação, conforme destacado no Quadro I.

Quadro I: Momentos da Reflexão

\begin{tabular}{|l|l|}
\hline Reflexão na ação & $\begin{array}{l}\text { É uma reflexão presente na vida dos profissionais, sendo efetivada } \\
\text { quando o profissional conduz sua prática, tendo em vista que } 0 \\
\text { profissional cria estratégias no momento de sua prática para soluções } \\
\text { de problemas na aprendizagem. }\end{array}$ \\
\hline $\begin{array}{l}\text { Reflexão sobre a } \\
\text { ação }\end{array}$ & $\begin{array}{l}\text { Tem caráter retrospectivo em relação à reconstrução de sua prática } \\
\text { anterior, ajudando o professor a refletir sobre como foi sua ação, os } \\
\text { meios que a conduziram, os problemas que obteve, as estratégias que } \\
\text { usou para resolver esses problemas e, com base nesse procedimento, } \\
\text { busca novos meios para que sua prática posterior seja melhor efetivada. }\end{array}$ \\
\hline $\begin{array}{l}\text { Reflexão sobre a } \\
\text { reflexão na ação }\end{array}$ & $\begin{array}{l}\text { A reflexão sobre a reflexão na ação reflete sobre as duas articulações } \\
\text { anteriores, de modo que o profissional possa se precipitar para suas } \\
\text { próximas práticas, ou seja, possibilita ao professor refletir sobre suas } \\
\text { ações anteriores e projetar um horizonte com novas práticas. }\end{array}$ \\
\hline
\end{tabular}

Fonte: Elaboração dos Autores

Alarcão (2011), ao analisar estes momentos de reflexão, ressalta que para que o professor possa dominar esse último momento de reflexão, quer seja, a reflexão sobre a reflexão na ação, ele pode lançar mão de quatro estratégias em sua prática docente, que são:

- A análise de casos - por meio dessa estratégia são evidenciados acontecimentos na prática do professor que merecem, além de atenção, uma reflexão sobre como foram conduzidos, sendo uma reflexão sobre a ação, levantando os casos que surpreenderam o professor durante sua prática, positiva ou negativamente, e que poderão ser reconstruídos. 
- A narrativa - essa estratégia caminha junto com a análise de casos, pois o professor relata os acontecimentos de sua prática, podendo analisá-los mais profundamente, levando isso adiante para ter melhor conclusão de sua prática profissional e sempre viabilizando 0 conhecimento.

- Os portfólios - os portfólios são fundamentais para que o professor analise os acontecimentos e resultados obtidos, promovendo o desenvolvimento reflexivo, estimulando o processo de enriquecimento conceitual e facilitando os processos de auto avaliação.

- As perguntas pedagógicas - as perguntas pedagógicas se efetivam quando o professor questiona o meio social em que está inserido e o motivo pelo qual não consegue mudar sua prática, propiciando a compreensão de alternativas válidas para que mude sua prática, valorizando o ensino e a aprendizagem.

As discussões acerca da reflexão sobre a reflexão na ação também são destacadas no trabalho de Shön (1992, p. 83), quando ele afirma que

[...] é possível olhar retrospectivamente e refletir sobre a reflexão-na-ação. Após a aula, o professor pode pensar no que aconteceu, no que observou, no significado que Ihe deu e na eventual adoção de outros sentidos. Refletir sobre a reflexão-na-ação é uma ação, uma observação e uma descrição, que exige o uso de palavras.

A partir destas discussões, propostas por Alarcão (2011) e Shön (1992, 2000), podemos observar que a formação de um profissional reflexivo deve passar por estratégias que analisam diretamente as questões do cotidiano, buscando meios para a resolução de problemas, sendo que o professor deve interagir com o contexto e não apenas ficar isolado em uma aula tradicional, e, por meio da reflexão, buscar meios que revigorem sua prática, contribuindo tanto para uma melhor aprendizagem de seus alunos quanto para que eles percebam qual a função da escola em nossa sociedade.

Assim, entendemos que a reflexão abarca um aspecto pessoal para o sentido da profissão docente e sua atuação enquanto professor. Para Alarcão (1996, p. 177),

[...] ser professor implica saber quem sou, as razões pelas quais faço $o$ que faço $\mathrm{e}$ conscientizar-me do lugar que ocupo na sociedade. Numa perspectiva de promoção do estatuto da profissão docente, os professores têm de ser agentes ativos de seu próprio desenvolvimento e do funcionamento das escolas como organização ao serviço do grande projeto social que é a formação dos educandos. 
As discussões apresentadas até aqui nos permitem compreender quais são as características que um professor reflexivo deve ter, e esse referencial teórico é que nos permitiu fazer as inferências necessárias para identificar, no discurso do professor, elementos que pudessem ser articulados com a temática envolvendo o professor reflexivo.

\section{Desenho metodológico da investigação}

A investigação que realizamos é tomada como sendo de cunho qualitativo (SANDíN ESTEBAN, 2010), e caracterizada pela subjetividade e interpretação que ocorre durante os momentos da investigação, haja vista o cerne de nossa discussão que está no discurso do professor. Ressaltamos, assim, que os dados obtidos de nossa pesquisa foram todos narrativos e descritivos

Esta investigação foi orientada, ainda, pela concepção do estudo de caso com abordagem interpretativa, considerando o estudo de caso como uma análise mais direcionada e compreensiva de um fenômeno (SANDÍN ESTEBAN, 2010).

Em nossa pesquisa, nos apoiamos, também, nas premissas discutidas por Oliveira (2008), para quem a pesquisa qualitativa tem como característica a análise e interpretação dos dados, sem que haja a necessidade de se considerar aspectos quantitativos relativos aos mesmos.

Destacamos, ainda, que não tivemos a preocupação em definir evidências a priori para então ir em busca de comprovar hipóteses. As interpretações foram se construindo à medida em que começamos a analisar os dados.

Para que a produção de dados fosse significativa para nossa investigação, selecionamos alguns professores que atuaram como sujeitos dessa investigação. Para selecionar estes professores, levamos em consideração dois fatores: (i) que eles não atuassem todos no mesmo nível de ensino e; (ii) que a partir de uma conversa inicial se autodeclarassem ser professores reflexivos. Estes fatores foram determinados pelo nosso interesse em analisar o discurso de professores que atuam em diferentes níveis de ensino e que, por esse motivo, possam ter experiências e formações diferentes que tenham contribuído para sua crença em ser um professor reflexivo.

Destacamos, assim, que os sujeitos dessa pesquisa são professores que ensinam Matemática, atuam na rede pública do município de Guarulhos e se consideram professores 
reflexivos. Ressaltamos, ainda, que tivemos contato com vários professores de diferentes níveis de ensino, mas apenas quatro professores aceitaram participar da pesquisa, sendo um dos Anos Iniciais e um dos Anos Finais do Ensino Fundamental, um do Ensino Médio e um do Ensino Superior.

Como destacamos anteriormente, o grupo que participou de nossa pesquisa foi composto de quatro professores, sendo duas mulheres e dois homens, com faixa etária entre vinte e quatro anos e sessenta anos. Para uma melhor identificação desses sujeitos passamos a apresentar algumas de suas características ${ }^{1}$ :

- Professora Sophia - Possui entre cinquenta e cinquenta e nove anos de idade e tem entre dezesseis e vinte anos de experiência como docente, sendo que na escola na qual está atualmente tem entre onze e quinze anos de atuação. É formada em Biologia e pósgraduada em Pedagogia e, segundo ela, participou de alguma atividade de formação continuada nos últimos dois anos.

- Professora Marta - Possui entre vinte e trinta e nove anos de idade e trabalha como professora há menos de um ano. É licenciada em Matemática e, segundo ela, não participou de nenhuma atividade de formação continuada nos últimos dois anos.

- Professor Jair - Possui entre quarenta e quarenta e nove anos de idade e tem entre seis e nove anos de experiência como professor, sendo de um a dois anos na escola que leciona atualmente. Sua titulação é de mestre e, segundo ele, participou nos últimos dois anos de cursos de formação continuada.

- Professor Lucas - Tem entre trinta e trinta e nove anos de idade e pussio entre seis e nove anos de experiência, sendo de um a três anos na instituição que leciona atualmente. Sua titulação é de mestre e, segundo ele, participou nos últimos dois anos de cursos de formação continuada.

Tendo como base que esta pesquisa tem caráter qualitativo, os instrumentos selecionados para a produção de dados foram:

Entrevistas: A entrevista adotada para a realização desse trabalho foi a semiestruturada, e é caracterizada por Oliveira (2008) como tendo sua parte inicial pré-estabelecida, e uma segunda parte composta de perguntas abertas aos professores, ou seja, provida de questionamentos não

\footnotetext{
1 Para garantir o anonimato dos professores, utilizamos nomes fictícios.
} 
pré-estabelecidos no decorrer dela. Por meio dessa entrevista levantamos dados em relação à formação desses professores, assim como algumas características que diziam adotar em sua prática, além de seu discurso em relação a ser um professor reflexivo e o porquê se considera um professor reflexivo.

Questionário: O questionário elaborado para os professores foi fechado, conhecido como questionário estruturado, sendo caracterizado por Nogueira (2002) como um questionário que se apresenta de uma forma mais rígida que o aberto, e seu intuito foi o de conhecer as características pessoais e da formação dos professores, como idade, tempo como professor, a mais alta titulação, entre outros.

\section{Analisando os dados}

Durante as entrevistas, com a finalidade de produzir narrativas que nos possibilitassem fazer inferências sobre o porquê os professores, sujeitos de nossa investigação, consideravam-se professores reflexivos, deparamo-nos com uma preocupação de alguns deles em associar 0 professor reflexivo ao fato de ser uma característica de um bom professor. Este fato nos levou a novas leituras e, em Pimenta e Lima (2004), encontramos uma discussão que destaca que para ser um bom professor o docente deve basear sua prática e suas reflexões de acordo com a necessidade da comunidade, pois deve possuir interpretações conforme os contextos, momentos históricos e sociais e valores que a comunidade que está presente na instituição atribui à educação, pois, segundo elas, o conceito de bom professor é um conceito polissêmico.

A discussão proposta por essas autoras nos chama atenção para o fato de que refletir sobre a prática vai além da preocupação com o espaço de sala de aula; há a necessidade de se considerar o contexto no qual a escola está inserida, pois este deverá, necessariamente, nortear a prática do professor.

Apesar desta preocupação, por vezes, estar no discurso de alguns professores nas escolas, destacamos que, em nossa investigação, nenhum professor considerou, diretamente, este aspecto em suas entrevistas. Se entendermos que uma forma de conhecer a comunidade e o contexto no qual a escola está inserida reside na maior participação e envolvimento dos pais ou responsáveis pelos alunos com a escola, então podemos destacar a fala da professora Sofia, quando ela diz: 
Considero que falta na escola a interação dos pais, principalmente quando em uma escola pública esta é vista como algo que não precisa de esforço e dedicação por parte deles. O contrário, se fosse uma escola privada, o interesse seria muito maior em relação à aprendizagem do filho. Quando eu pergunto para os meus alunos se fizeram a lição de casa, por exemplo, as respostas são: "eu fui ao centro de Guarulhos", "eu fui à casa do meu tio", "eu fui à casa da minha tia e não deu tempo de fazer". Se o pai se preocupasse um pouquinho conseguiria um tempo para o aluno fazer as lições quando não está em casa, ou seja, falta muito o estudo incentivado pelos pais (fala da professora Sofia).

A professora Sofia, durante a entrevista, mostrou sua preocupação com a falta de participação dos pais ou responsáveis nas atividades dos alunos. Para ela, esse distanciamento tem um grande impacto no processo de ensino e aprendizagem, ou seja, diretamente em suas aulas. Neste sentido, para ela, refletir sobre sua prática passa por uma reflexão sobre o contexto no qual o aluno está inserido, passando a ser importante considerar os momentos e valores sociais e culturais da comunidade, que são refletidos em sala de aula.

Ferreira (2001) destaca que a reflexão é um ato que designa uma ação que voltará a ser praticada a partir de uma retrospectiva do que se fez e a identificação do que será possível ser melhorado, privilegiando, assim, ações para novos conceitos e atitudes, sempre tendo um foco principal: adaptar ainda mais todas as ações que deram certas e corrigir tudo aquilo que for necessário.

Durante nossa investigação podemos destacar as falas de alguns professores que podem ser articuladas com a discussão de Ferreira (2001). Por exemplo, o professor Lucas nos disse:

A reflexão eu enxergo como a conversa comigo mesmo, a busca por respostas de perguntas que nós nos fazemos e talvez não conhecemos as respostas, ou seja, uma busca pela incerteza. Sobre ações de reflexão na minha prática eu reflito numa única pergunta que me faço após toda aula, se eu fosse aluno, eu gostaria da aula que acabei de dar? Esse é meu ponto de partida, quando eu não gostei da minha aula, então esse é um grande ponto para minha reflexão (fala do professor Lucas).

A fala do professor Lucas revela uma estratégia de reflexão que acontece distante da ação, ou seja, neste momento, o professor não está interagindo com alunos, pais ou colegas, e passa a refletir sobre o que aconteceu, sobre o que ele fez e sobre os resultados do que ele fez. Esta forma de reflexão, associada à discussão proposta por Ferreira (2001), pode ser vista como uma reflexão simultaneamente retrospectiva e prospectiva.

Este tipo de reflexão também pode ser percebido na fala do professor Jair, quando ele diz: 
Eu acredito que seja uma análise de resultados, ou seja, tudo que se faz, deve-se analisar os resultados e, também, do ponto de vista das atitudes, do que eu fiz, o que eu posso fazer a fim de melhorar as aulas (Fala do professor Jair).

Reflexões desta natureza, como as destacadas no discurso dos professores Lucas e Jair, podem levar o professor a fazer uso de narrativas, como destaca Alarcão (2011), como forma de relatar os acontecimentos de sua prática para analisá-los mais profundamente. As narrativas destes professores revelam a intencionalidade de professores que estão constantemente analisando suas práticas que reflete, constantemente, sobre suas posturas em sala de aula. Esta característica de reflexão é apresentada por Shön (2000) como uma reflexão sobre a ação, haja vista o seu caráter retrospectivo e prospectivo.

A forma como estes professores relataram os momentos de suas reflexões nos permitiram concluir que estes momentos são, essencialmente, momentos individuais de reflexão sobre suas práticas. Apesar de ser entendido como um momento importante para o professor, e necessário para o processo de reflexão, Alarcão (2011) nos alerta sobre a importância de o professor discutir com outros docentes, e até mesmo com a gestão, sua prática docente, para que sua reflexão seja mais aprofundada, haja vista que ser um professor reflexivo individualmente pode levar a frustação e solidão, enquanto que o coletivo pode contribuir para um objetivo comum, que é a melhoria da educação.

Buscando identificar, nas narrativas dos professores, se esta prática fazia parte do cotidiano deles, perguntamos a eles se havia uma prática de se discutir com outros docentes, ou com a gestão, sobre as suas metodologias adotadas em sua prática, e como era o processo de reflexão sobre esta ação. Os professores Marta e Jair responderam a este questionamento. 0 professor Jair nos disse:

Em parte sim, pois nessa instituição, apesar da estrutura estar longe do ideal, nós nos comunicamos sempre que possível, como na reunião do ensino médio, [quando] conseguimos conversar um pouco, porém, o tempo que levamos com assuntos burocráticos e recados é muito maior do que o tempo que poderíamos discutir sobre assuntos pedagógicos. Uma das maneiras que conversamos é quando aplicamos trabalhos interdisciplinares, porque o currículo já prevê isso e assim nos comunicamos sobre os assuntos que estamos ensinando, mesmo assim acho que é menos do que poderíamos conversar (fala do professor Jair).

A fala do professor Jair, assim como a da professora Marta, descrita a seguir, revelam suas preocupações, entretanto, não deixam clara suas posições sobre como estas discussões poderiam contribuir para suas reflexões sobre suas práticas. A professora Marta relatou que 
Sim, o coletivo é muito importante dentro da escola, mas nem sempre isso acontece. Está faltando um pouco de entrosamento dos professores e diálogos a respeito de suas práticas. Durante [as reuniões] não se referem à sala de aula, e além [disso] atendemos os pais e realizamos formações, logo há dificuldade de discutir as metodologias a serem aplicadas. Sobre a gestão, o diálogo é mais rápido, porém ainda consigo passar um pouco mais sobre as metodologias que aplico (fala da professora Marta).

A prática de reflexão individualizada recebeu críticas ao longo do tempo, e em Zeichner (1993) encontramos seu posicionamento a este respeito quando ele destaca que a reflexão, por ser uma prática social, deve abarcar o coletivo, e não somente o indivíduo. Neste sentido, entendemos que os momentos de diálogos entre os professores, e entre professores e gestores, deveriam ser incentivados a se tornarem, efetivamente, espaços nos quais os professores compartilhassem experiências e ideias.

Este processo contribuiria para possibilitar ao professor analisar, questionar e interpretar suas ações de forma sistemática, concebendo esse momento como um movimento de formação profissional aberto à consideração de um questionamento realizado pelo coletivo, capaz de conduzir o professor para a reconstrução de sua própria prática.

A reconstrução de sua própria prática é vista como uma consequência da ação de reflexão sobre a prática e, neste sentido, ela só seria possível para aqueles professores que exercem a reflexão sobre sua prática. Este, talvez, seja um dos motivos para as discussões acerca do processo de reflexão ser tomado como algo complexo, principalmente se assumirmos a premissa de que há professores que não são reflexivos.

Em relação a esta discussão, perguntamos aos professores como eles consideravam esta discussão, e se consideravam diferenças entre um professor que se considera reflexivo e outro que não se considera. Como resposta, apenas a professora Sofia relatou entender que todos os professores refletem de algum modo. Entretanto, os demais professores pensam que a principal diferença entre eles é a existência de um comodismo por parte dos professores que não se consideram reflexivos. Podemos observar esse relato na fala do professor Lucas, ao dizer que

Um professor reflexivo considero que seja um professor inquieto, um professor que não fica satisfeito, um professor incomodado com a sensação de sua aula poder ser melhor, da sua instituição poder ser melhor, do seu país poder ser melhor, e a principal diferença para um [professor] não reflexivo é que este é acomodado, pois acredito que ele perca a reflexão (Fala do professor Lucas). 
Segundo Alarcão (2011), ser professor reflexivo é muito importante, pois o professor deve atender as necessidades dos alunos, bem como conseguir atender uma sociedade que se encontra em constante transformação. Ao buscar articular as ideias dessa autora com o discurso dos professores, podemos destacar a fala da professora Marta, ao afirmar que

ser um professor reflexivo é importante, porque o aluno muda, a escola muda e a postura de cada um muda. Então, não adianta ser mecânico, pois não devemos formar pessoas que se farão ignorantes, mas sim pessoas que pensam (Fala da professora Marta).

Entendemos que a reflexividade do professor deve perpassar a conscientização teórica e crítica de sua realidade e, por esta razão, o professor deve se apropriar de teorias que forneçam subsídios para a sua prática, contribuindo para a compreensão das diferentes situações institucionais, políticas e sociais nas quais ocorrem as práticas escolares (LIBÂNEO, 2002). Neste sentido, o professor deve reconhecer a importância de uma formação que não seja pautada apenas em conhecimentos específicos de sua área de atuação, haja vista que o conhecimento advindo de outras áreas deverá contribuir para sua reflexão em sala de aula.

Assim, ao analisar as narrativas do professor Lucas, observamos que sua formação sempre foi mais voltada para os aspectos da Matemática. Por exemplo, quando perguntamos se ele já havia estudado ou discutido, em algum momento, algo relacionado à temática sobre professor reflexivo, ele nos disse:

Não, nenhuma [discussão] particular que tenha me chamado a atenção. E nem mesmo na graduação, pois meus estudos sempre foram mais voltados para a Matemática (fala do professor Lucas).

E, em um outro momento, referindo-se se já havia participado de alguma formação que tivesse abordado esta temática, completou:

Não. Desde a época da graduação e, também, em uma pós-graduação. Eu sempre busquei mais conversas mais matemáticas. Não quer dizer que isso não seja tão importante quanto, mas eu tenho mais aptidão para Matemática, por conhecimento matemático (fala do professor Lucas).

O discurso deste professor pode ilustrar uma ideia pragmática que ainda é comum encontrarmos em nossa literatura, que se refere a alguns professores que consideram que os conhecimentos pedagógicos não são tão importantes, sendo o domínio dos conteúdos específicos 
de sua área de conhecimento o elemento essencial para se desenvolver um bom trabalho em sala de aula.

Em um processo de reflexão sobre sua prática, entendemos ser importante a análise deste discurso, pois assumimos que por mais qualificado que um professor seja em relação ao conteúdo específico de sua área,

[...] não há garantia de que a mesma tenha igual peso na construção do significado, dos saberes, das competências, dos compromissos e das habilidades referentes à docência e de que estejam preparados para conceber e implementar alternativas e soluções pedagógicas adequadas, diante dos problemas que surgem na aprendizagem de seus alunos (ANASTASIOU, 2002, p. 174).

\section{Considerações}

O objetivo deste trabalho foi o de apresentar uma investigação sobre o discurso de professores que se auto intitulam ser professores reflexivos e, a partir da interpretação das narrativas desses professores, buscar articular os seus discursos sobre elementos presentes na temática que envolve o professor reflexivo com o referencial teórico adotado para esta investigação.

A análise dos dados nos possibilitou inferir que estes professores, ao se veem como professores reflexivos, desenvolvem algumas ações, de fato, que apontam indícios sobre isso. Entretanto, as ações narradas pelos professores, em sua maioria, são identificadas em um nível micro de reflexão, geralmente relacionadas com o fato de uma atividade não ter sido muito boa ou a lista de exercícios ter sido muito extensa e não possível de resolvê-la durante o período planejado.

Consideramos que a falta de apropriação teórica sobre esta temática tenha contribuído para que estas ações permaneçam em um nível micro de reflexão. Entendemos que esta característica de reflexão sobre a prática pode ser vista como pertencente a um âmbito puramente técnico, contribuindo, apenas, para que o professor possa retificar um erro ou uma postura inadequada.

A realização deste trabalho nos possibilitou observar a necessidade de o professor olhar para si em um processo de reflexão crítica para que, de fato, ele possa avançar no processo de transformação de sua prática pedagógica a partir de sua própria transformação, haja vista que 0 
processo reflexivo não surge por acaso. Este processo não deve ser visto como fim em si mesmo, mas um meio possível e adequado para que possamos, enquanto professores, produzir um movimento de mudança na maneira de ser da educação.

\section{Referências}

ALARCÃO, Isabel. Professores reflexivos em uma escola reflexiva. 8. ed. São Paulo: Cortez, 2011. ALARCÃO, Isabel. Reflexão crítica sobre o pensamento de D. Schön e os programas de formação de professores. Revista da Faculdade de Educação, São Paulo, v. 22, n. 2, p 11-42, jul./dez. 1996.

ANASTASIOU, Léa das Graças Camargos. Construindo a docência no Ensino Superior: relação entre saberes pedagógicos e saberes científicos. In: ROSA, Dalva Eterna Gonçalves; SOUZA, Vanilton Camilo de. (Org). Didática e práticas de ensino: interfaces com diferentes saberes e lugares formativos. Rio de Janeiro; Goiânia: DP\&A; Alternativa, 2002, p. 173-187.

ARAUJO, Merlinda Pessoa. Formação docente: caminhos percorridos em busca de um processo. In: V ENCONTRO DE PESQUISA EM EDUCAÇÃO DA UFPI, 2008, Teresina. Anais: V EPEd: a escritura da pesquisa em Educação e suas diversas linguagens. Teresina: UFPI, 2008, p. 1-13.

DEWEY, John. Como pensamos - como se relaciona o pensamento reflexivo com o processo educativo: uma reexposição. Tradução de Haydée Camargo. São Paulo: Editora Nacional,1979.

FERREIRA, Marcos Artemio Fischborn. Trabalho infantil e produção acadêmica nos anos 90: tópicos para reflexão. Estudos de Psicologia, Natal, v. 6, n. 2, p. 213-225, jul./dez. 2001.

LIBÂNEO, José Carlos. Reflexividade e formação de professores: outra oscilação do pensamento pedagógico brasileiro? In: PIMENTA, Selma Garrido; GHEDIN, Evandro. (Org.) Professor reflexivo no Brasil: gênese e crítica de um conceito. São Paulo: Cortez, 2002, p. 53-79.

NEVES, Tatiane Garcia; BITTAR, Marilena. Análise da prática de um professor no ensino da matemática: possíveis reflexões em um processo. Em Teia, Recife, v. 5, n. 3, p. 1-23, 2015.

NOGUEIRA, Roberto. Elaboração e análise de questionário: uma revisão da literatura básica e a aplicação dos conceitos a um caso real. Rio de Janeiro: UFRJ/ COPPEAD, 2002.

OLIVEIRA, Cristiano Lessa. Um apanhado teórico-conceitual sobre a pesquisa qualitativa: tipos, técnicas e características. Travessias, Paraná, v. 2, n. 3, p. 1-16, set./dez. 2008.

PIMENTA, Selma Garrido; GHEDIN, Evandro. (Org.) Professor reflexivo no Brasil: gênese e crítica de um conceito. São Paulo: Cortez, 2002.

PIMENTA, Selma Garrido; LIMA, Maria Socorro Lucena. Estágio e docência. São Paulo: Cortez, 2004.

SANDIN ESTEBAN, Maria Paz. Pesquisa qualitativa em educação: fundamentos e tradições. Tradução de Miguel Cabrera. Porto Alegre: Artmed, 2010. 
SCHÖN, Donald. Educando o profissional reflexivo: um novo design para o ensino e a aprendizagem. Tradução de Roberto Cataldo Costa. Porto Alegre: Artmed, 2000.

SCHÖN, Donald. Formar professores como profissionais reflexivos. In: NÓVOA, Antonio. (Org.). Os professores e sua formação. Lisboa: Dom Quixote, 1992, p. 77-91.

ZEICHNER, Kenneth. A formação reflexiva de professores: ideias e práticas. Tradução de Afonso José Carmona Teixeira, Maria João de Carvalho, Maria Nóvoa. Lisboa: Educa, 1993. 